\title{
High expression of Sam68 in sacral chordomas is associated with worse clinical outcomes
}

\author{
This article was published in the following Dove Press journal: \\ OncoTargets and Therapy \\ 22 September 2017 \\ Number of times this article has been viewed
}

\author{
Hai Wen ${ }^{1, *}$ \\ Pengzhi Li $i^{1, *}$ \\ Hong $\mathrm{Ma}^{\prime}$ \\ Jiaoyun Zheng ${ }^{2}$ \\ Yipin Yu' \\ Guohua Lv' \\ 'Department of Spine Surgery, \\ The Second Xiangya Hospital of \\ Central South University, Changsha, \\ Hunan, China; ${ }^{2}$ Department of \\ Pathology, The Second Xiangya \\ Hospital of Central South University, \\ Changsha, Hunan, China \\ *These authors contributed equally \\ to this work
}

\begin{abstract}
Src-associated in mitosis of $68 \mathrm{kDa}$ (Sam68), also known as KHDRBS1 (KH domain-containing, RNA-binding, signal transduction-associated 1), is a member of the signal transduction and activation of RNA family. Previous studies have demonstrated that the aberrant expression of Sam68 is associated with the progression and prognosis of a variety of cancers, but little is known about its expression and role in chordomas, which are rare and aggressive bone neoplasms. In this study, we analyzed 40 tumor tissues and 20 distant normal tissues obtained from 40 patients with sacral chordoma using immunohistochemistry, and observed the expression of Sam68 was significantly upregulated in sacral chordomas compared with normal tissues $(P=0.001)$. A positive correlation between the expression of Sam68 and the cell proliferation index Ki-67 was determined using Spearman's rank correlation test $(\gamma=0.599, P<0.001)$. In addition, high expression of Sam68 was significantly associated with surrounding muscle invasion $(P<0.001)$. Moreover, Kaplan-Meier curves showed that patients with overexpressed Sam68 had shorter local recurrence-free survival time $(P<0.001)$. Lastly, multivariate analysis indicated that Sam68 is an independent prognostic factor for the local recurrence-free survival of sacral chordomas (hazard ratio $=5.929,95 \%$ CI: $1.092-32.188, P=0.039$ ). Our findings suggest the use of Sam68 as a predictor for the recurrence of sacral chordomas.
\end{abstract}

Keywords: sacral chordoma, Sam68, recurrence, prognostic factor

\section{Introduction}

Chordomas are rare malignant bone neoplasms that are thought to arise from embryonic remnants of the notochord, with an annual incidence of $\sim 1 / 1,000,000$ all over the world. ${ }^{1-3}$ Chordomas are characterized by severe aggressiveness and a high rate of local recurrence. ${ }^{46}$ The overall 5- and 10-year survival rates following surgical resection are $45 \%-77 \%$ and $28 \%-50 \%$, respectively. ${ }^{3,7-9}$ Most patients ultimately die of exhaustion from repeated surgeries and fatal destruction of local tissues. Also, $50 \%-60 \%$ chordomas occur at the sacrum and often reach a large size due to their indolent symptoms and slow growth. ${ }^{5,10}$ Surgery remains the mainstay of treatment due to the poor sensitivity of chordomas to chemotherapy and radiotherapy; ${ }^{11-14}$ however, patients have a high risk of local recurrence even after surgical excision with wide resection margins. ${ }^{14-15}$ Therefore, the development of therapeutic strategies is highly needed for patients affected by chordoma.

Src-associated in mitosis of $68 \mathrm{kDa}$ (Sam68), also known as KHDRBS1 (KH domain-containing, RNA-binding, signal transduction-associated 1), is a member of the signal transduction and activation of RNA family, which has been demonstrated to transform cells to an oncogenic state. ${ }^{16,17}$ Using its RNA-binding property, Sam68 regulates a variety of cellular processes, including RNA splicing, RNA stability, RNA nuclear export and neuronal activity. ${ }^{18-28}$ Sam68 was also identified as a signaling

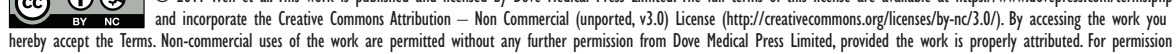
for commercial use of this work, please see paragraphs 4.2 and 5 of our Terms (https://www.dovepress.com/terms.php). 
molecule in multiple signaling pathways, such as NF- $\kappa \mathrm{B}$ activation and apoptosis signaling by the tumor necrosis factor receptor. ${ }^{29,30}$ Moreover, several cancer-relevant proteins including Bcl-x, cyclin D1b and CD44 are targets of Sam68. ${ }^{31-34}$ High expression of Sam68 is associated with poor prognosis of various malignancies, and its depletion by siRNA induces cell cycle arrest and restrains cell proliferation. ${ }^{35-39}$ Sam68 also plays a tumor-suppressive role in certain cancers; for example, high expression of Sam68 leads to cell cycle arrest and apoptosis in NIH-3T3 fibroblasts. ${ }^{40}$ Thus, the effects of Sam 68 on different cancers are double sided. However, the expression and role of Sam68 in chordomas are not well understood.

In this study, we investigated the expression of Sam68 in sacral chordomas compared with normal tissues using immunohistochemistry, and evaluated the association between Sam68 expression and the clinicopathologic features and prognosis of patients with sacral chordoma.

\section{Materials and methods}

\section{Patients and tissue samples}

In this study, we enrolled 40 patients ( 23 males and 17 females) who were diagnosed with sacral chordoma and received surgical treatment in the Department of Spine Surgery, The Second Xiangya Hospital of Central South University (Changsha, China) between January 2005 and October 2015. The mean age of patients was 55.1 years (range, 29-74 years). They were not treated by tumor-specific therapy including radiotherapy and chemotherapy before surgery. Clinicopathologic data including age and gender of the patients; tumor location, size, grade and stage; tumor invasion of the surrounding muscles; and the type of surgical resection were obtained from patients' medical records, retrospectively. Tumor grade and stage were evaluated based on the Enneking staging system for the surgical staging of malignant bone and soft tissue tumors. ${ }^{41,42}$ Resected specimens were assessed either as Enneking appropriate or Enneking inappropriate by anatomic pathologists, according to the Enneking principles. ${ }^{43}$ Tumor invasion of the surrounding muscles was determined using preoperative magnetic resonance imaging and histologic examination of tissues. ${ }^{44}$ In addition to the tumor tissues, we also obtained 20 distant normal tissues at least $3 \mathrm{~cm}$ from the resection margins as a control. The tissues were fixed into $10 \%$ buffered formalin immediately after surgery and embedded in paraffin. The paraffin blocks were subsequently cut into $4 \mu \mathrm{m}$ thick slices for immunohistochemical staining. Tumor diagnosis was confirmed by two experienced pathologists through histologic examination of hematoxylin and eosin-stained sections. The study was approved by the Ethical
Committee of The Second Xiangya Hospital of Central South University, and written informed consent was obtained from each patient for this study.

\section{Follow-up}

After the primary surgery, patients were followed up every 3 months during the first 2 years, every 6 months in the next 3 years and annually thereafter, and they received clinical and radiographic examinations each time until October 2016. Tumor recurrence was diagnosed by analyzing clinical manifestation and imaging results. The interval between the primary surgery and the first incidence of local tumor recurrence or death from any cause was defined as the local recurrence-free survival (LRFS) or the overall survival (OS), respectively.

\section{Immunohistochemistry}

Tissue slices were dewaxed in xylene and rehydrated by passage through a series of ethanol solutions; subsequently, the tissues were immersed in $0.01 \mathrm{M}$ citrate buffer $(\mathrm{pH}$ 6.0) and heated in a microwave oven at $121^{\circ} \mathrm{C}$ for $15 \mathrm{~min}$ to retrieve antigen activity. Potential endogenous peroxidase activity was quenched in $3 \%$ hydrogen peroxide for $10 \mathrm{~min}$. After rinsing with PBS, tissue sections were blocked with $10 \%$ normal goat serum at room temperature for $10 \mathrm{~min}$. Subsequently, they were incubated overnight at $4^{\circ} \mathrm{C}$ with primary antibodies, antiSam68 (1:100; Santa Cruz Biotechnology, Dallas, TX, USA) or anti-Ki-67 (1:100; Abcam, Cambridge, UK). The negative controls were not incubated with primary antibodies. The next day, tissue sections were rinsed with PBS three times, followed by $30 \mathrm{~min}$ incubation at $37^{\circ} \mathrm{C}$ with polymerized horseradish peroxidase-conjugated anti-rabbit IgG (Boster, Wuhan, China). Antibody binding was visualized using $3,3^{\prime}$-diaminobenzidine solution. The sections were finally counterstained with hematoxylin and were mounted for observation.

\section{Immunohistochemical evaluation}

Two experienced and independent pathologists who were blinded to the patients' clinicopathologic data evaluated and scored the immunostained sections using a semi-quantitative assessment reported previously. ${ }^{45}$ In each section, five highpower fields were randomly chosen and at least 300 cells per field were counted. Cells with immunostained brown nucleus were considered positive for Sam68 or Ki-67 expression. The immunoreactivity score for Sam68 expression was calculated by multiplying the staining intensity, established as 0 (no staining), 1 (weak staining), 2 (moderate staining) or 3 (strong staining), by the percentage of positive tumor cells, established as $0(<1 \%), 1(1 \%-10 \%), 2(11 \%-50 \%)$ 
or $3(>50 \%)$, resulting in scores ranging from 0 to 9 ; the level of Sam68 expression was divided into low (0-3) and high (4-9) for survival analysis. ${ }^{46}$ As described previously, ${ }^{45} \mathrm{Ki}-67$ index was defined as the percentage of Ki-67-positive cells and categorized as a low $(<10 \%)$ or high $(\geq 10 \%)$ index.

\section{Statistical analysis}

All statistical analyses were conducted with SPSS 19.0 (IBM Corporation, Armonk, NY, USA). The $\chi^{2}$ or Fisher's exact test was used appropriately to examine either the difference in Sam68 expression between the tumor and normal tissues or the association between Sam68 expression and patients' clinicopathologic characteristics. Spearman's rank correlation test was used to assess the correlation between Sam68 expression and Ki-67 index. The association between each parameter and LRFS or OS was analyzed by log-rank test and shown by Kaplan-Meier curves. Multivariate analysis was subsequently performed by Cox's proportional hazard model to identify the independent prognostic factors. A $P$-value $<0.05$ was considered statistically significant.

\section{Results}

\section{Upregulation of Sam68 expression and its positive correlation with $\mathrm{Ki}-67$ index in sacral chordomas}

We first compared the expression of Sam68 in 40 sacral chordoma tissues and 20 distant normal tissues using immunohistochemistry. As shown in Figure 1, Sam68 is prominently expressed in the nucleus of positive cells. A high level of Sam68 (Figure 1C) was scored in 60\% (24/40) of tumor tissues
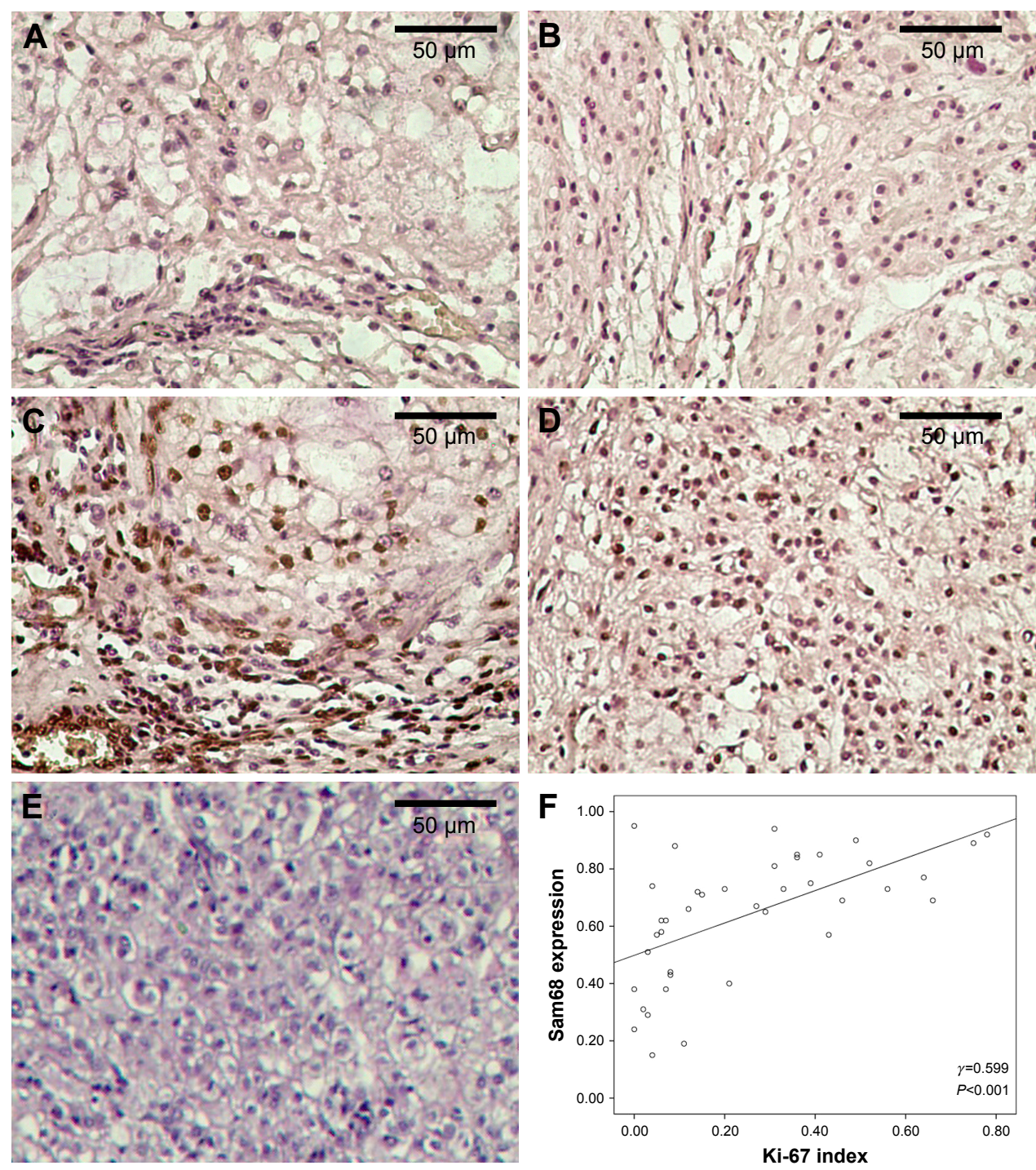

Figure I Representative expression of Sam68 and Ki-67 and their correlation in sacral chordomas.

Notes: (A) Low expression of Sam68; (B) low expression of Ki-67; (C) high expression of Sam68; (D) high expression of Ki-67; (E) negative control. All magnification, $\times 400$. (F) Positive correlation between Sam68 expression and Ki-67 index in sacral chordomas using Spearman's rank correlation test. 
Table I Expression of Sam68 in sacral chordomas compared with distant normal tissues

\begin{tabular}{lllll}
\hline Tissue samples & Total & \multicolumn{2}{l}{ Sam68 expression } & P-value \\
\cline { 3 - 4 } & & High (\%) & Low (\%) & \\
\hline Sacral chordomas & 40 & $24(60)$ & $16(40)$ & 0.001 \\
Distant normal tissues & 20 & $3(15)$ & $17(85)$ & \\
\hline
\end{tabular}

and $15 \%(3 / 20)$ of normal tissues, whereas $40 \%(16 / 40)$ of tumor tissues and $85 \%(17 / 20)$ of normal tissues expressed a low level of Sam68 (Figure 1A), respectively. Sam68 expression was significantly upregulated in sacral chordomas compared with normal tissues ( $P=0.001$; Table 1$)$. Additionally, we examined the expression of Ki-67, a widely used cell proliferation index in sacral chordoma tissues. There were 16 tumor tissues with a low Ki-67 index (Figure 1B) and 24 tumor tissues with a high Ki-67 index (Figure 1D). No positive cells were observed in negative control (Figure 1E). It was found that tumor tissues with a high Ki-67 index had significantly higher level of Sam68 $(P<0.001$; Table 2$)$. Moreover, a positive correlation between Sam68 expression and Ki-67 index $(\gamma=0.599, P<0.001$; Figure $1 F)$ was demonstrated using Spearman's rank correlation test.

\section{Association between Sam68 expression and the clinicopathologic characteristics of patients with sacral chordoma}

The association between Sam68 expression and the clinicopathologic characteristics of patients with sacral chordoma was assessed by the $\chi^{2}$ or the Fisher's exact test, as appropriate. In addition to Ki-67 index, Sam68 expression was significantly associated with surrounding muscle invasion $(P<0.001$; Table 2$)$ and the type of tumor resection $(P=0.006$; Table 2). No statistically significant association was observed between Sam68 expression and other clinicopathologic characteristics (Table 2).

\section{Association between Sam68 expression and the prognosis of patients with sacral chordoma}

During the period of follow-up, 27 (67.5\%) patients had local tumor recurrence and $16(40 \%)$ patients died, with a median LRFS of 18 months (range, 5-45 months) and a median OS of 47 months (range, 12-141 months). Kaplan-Meier curves demonstrated that a high level of either Sam68 $(P<0.001$; Figure 2A and Table 3) or Ki-67 ( $P=0.016$; Figure 2B and Table 3) was significantly associated with shorter LRFS time. Additionally, patients with low Sam68/Ki-67 coexpres-
Table 2 Association between Sam68 expression and the clinicopathologic characteristics of patients with sacral chordoma

\begin{tabular}{|c|c|c|c|c|}
\hline \multirow[t]{2}{*}{ Variables } & \multirow[t]{2}{*}{ Total } & \multicolumn{2}{|c|}{ Sam68 expression } & \multirow[t]{2}{*}{$P$-value } \\
\hline & & High & Low & \\
\hline \multicolumn{4}{|l|}{ Age (years) } & 0.505 \\
\hline$<50$ & 15 & 10 & 5 & \\
\hline$\geq 50$ & 25 & 14 & 11 & \\
\hline \multicolumn{4}{|l|}{ Gender } & 0.601 \\
\hline Male & 23 & 13 & 10 & \\
\hline Female & 17 & 11 & 6 & \\
\hline \multicolumn{4}{|l|}{ Tumor location } & 0.292 \\
\hline Above S3 & 24 & 16 & 8 & \\
\hline S3 and below & 16 & 8 & 8 & \\
\hline \multicolumn{4}{|l|}{ Tumor size $(\mathrm{cm})$} & 0.343 \\
\hline$<5$ & 14 & 7 & 7 & \\
\hline$\geq 5$ & 26 & 17 & 9 & \\
\hline \multicolumn{4}{|l|}{ Tumor grade } & $0.58 \mathrm{I}$ \\
\hline High & 27 & 17 & 10 & \\
\hline Low & 13 & 7 & 6 & \\
\hline \multicolumn{4}{|l|}{ Tumor stage } & $0.129 *$ \\
\hline IA & 9 & 3 & 6 & \\
\hline IB & 4 & 4 & 0 & \\
\hline$\| \mathrm{A}$ & 4 & 2 & 2 & \\
\hline IIB & 20 & 12 & 8 & \\
\hline III & 3 & 3 & 0 & \\
\hline \multicolumn{4}{|c|}{ Surrounding muscle invasion } & $<0.001$ \\
\hline Yes & 25 & 21 & 4 & \\
\hline No & 15 & 3 & 12 & \\
\hline \multicolumn{4}{|l|}{ Type of resection } & 0.006 \\
\hline EI & 18 & 15 & 3 & \\
\hline EA & 22 & 9 & 13 & \\
\hline \multicolumn{4}{|l|}{ Ki-67 index } & $<0.001$ \\
\hline High & 24 & 21 & 3 & \\
\hline Low & 16 & 3 & 13 & \\
\hline
\end{tabular}

Note: *Using the Fisher's exact test.

Abbreviations: EA, Enneking appropriate; El, Enneking inappropriate.

sion had an increased LRFS time $(P<0.001$; Figure 2C), whereas those with high Sam68/Ki-67 coexpression had a reduced LRFS time $(P=0.002$; Figure 2D). Shorter LRFS time was also observed in patients with higher tumor stage $(P<0.001$; Table 3 and Figure 2E), surrounding muscle invasion $(P<0.001$; Table 3 and Figure $2 \mathrm{~F})$ and Enneking inappropriate resection $(P<0.001$; Table 3 and Figure $2 \mathrm{G})$. Moreover, worse OS was related to higher tumor stage $(P<0.001$; Figure $3 \mathrm{~A}$ and Table 4$)$, surrounding muscle invasion $(P=0.032$; Figure 3B and Table 4$)$ and Enneking inappropriate resection ( $P=0.015$; Figure $3 \mathrm{C}$ and Table 4 ), whereas there was no association between Sam68 expression and OS $(P=0.228$; Table 4). Finally, the factors associated with the LRFS or OS were included in the multivariate analysis using Cox's proportional hazard model. The results indicated that Sam68 expression (hazard ratio $[\mathrm{HR}]=5.929,95 \% \mathrm{CI}$ : 1.092-32.188, $P=0.039$; Table 3$)$, tumor stage $(\mathrm{HR}=2.272$, 
95\% CI: $1.384-3.729, P=0.001$; Table 3 ), surrounding muscle invasion ( $\mathrm{HR}=13.128,95 \% \mathrm{CI}$ : 2.793-61.698, $P=0.001$; Table 3 ) and the type of tumor resection (HR $=6.678,95 \%$ CI: 2.052-21.736, $P=0.002$; Table 3) were the independent prognostic factors for the LRFS, whereas tumor stage (HR $=1.677,95 \%$ CI: 1.002-2.806, $P=0.049$; Table 4) was the only independent prognostic factor for the OS.

\section{Discussion}

Chordomas are slow-growing malignancies with a strong invasive ability and a high rate of local recurrence. ${ }^{47}$ Obtaining

A

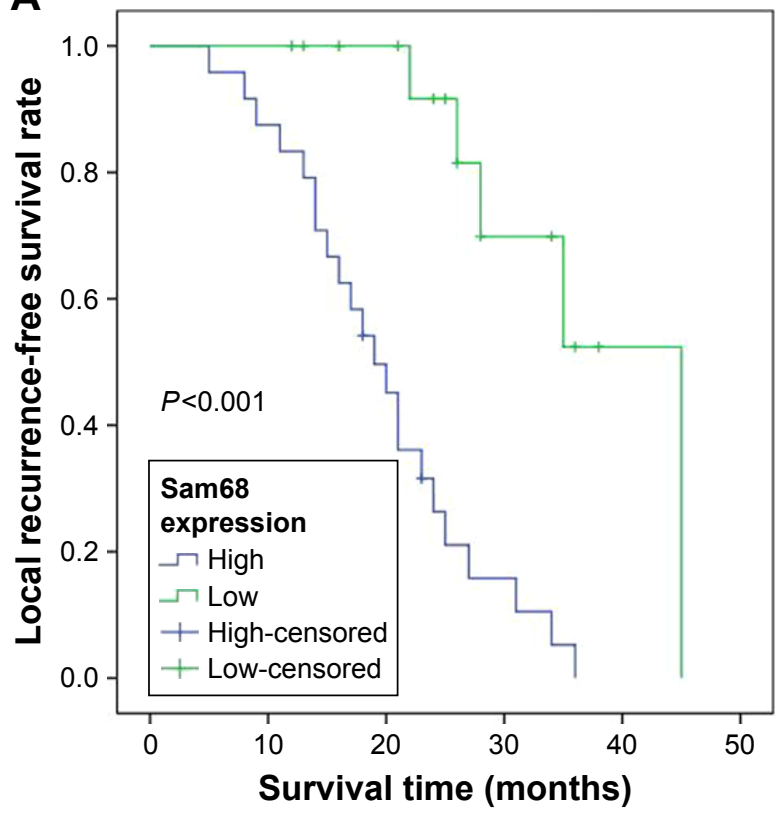

C

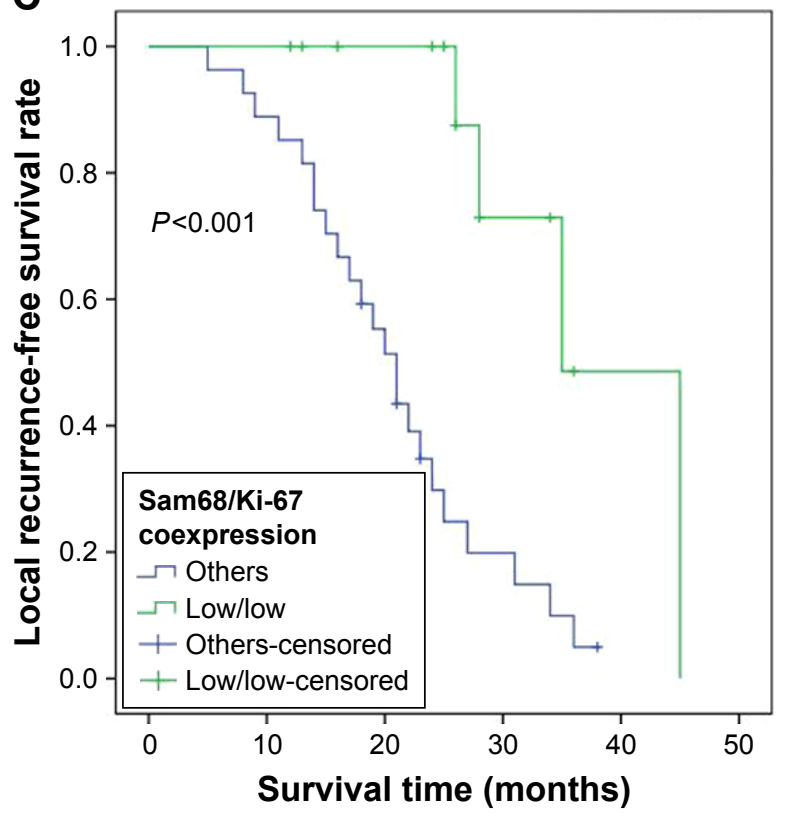

wide resection margins is a key factor determining tumor recurrence and long-term prognosis; however, it is often technically difficult because of the proximity of the lesion to vital neurovascular structures and tumor invasion into the surrounding tissues. ${ }^{48}$ In order to achieve an improvement of tumor therapy, a lot of researchers have tried to identify novel biomarkers predicting the prognosis of patients. In this study, we demonstrated that Sam68 expression was significantly upregulated and positively correlated with the expression of cell proliferating index Ki-67 in sacral chordomas. Additionally, high expression of Sam68 was significantly associated

\section{B}

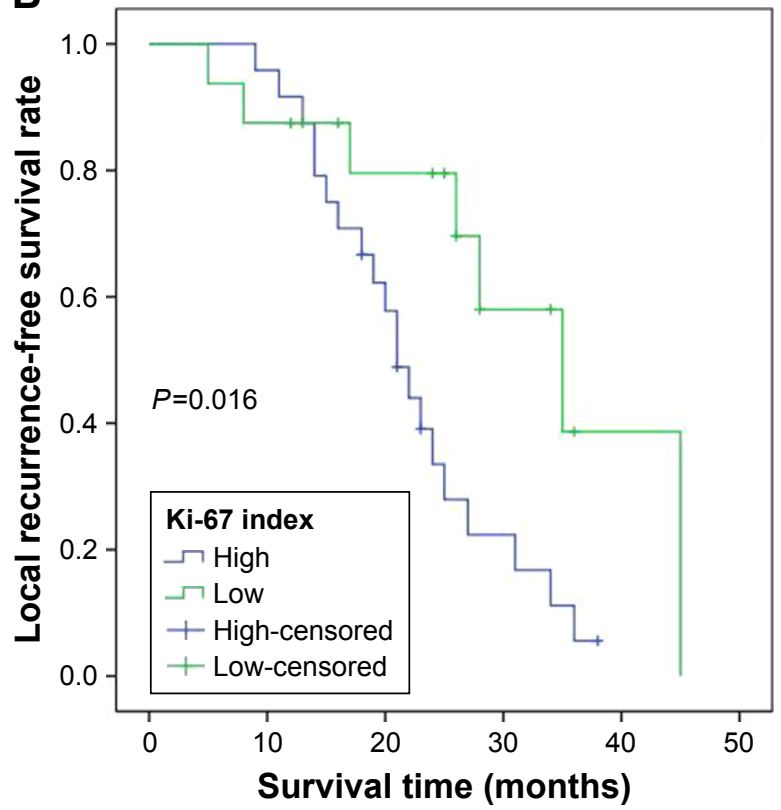

D

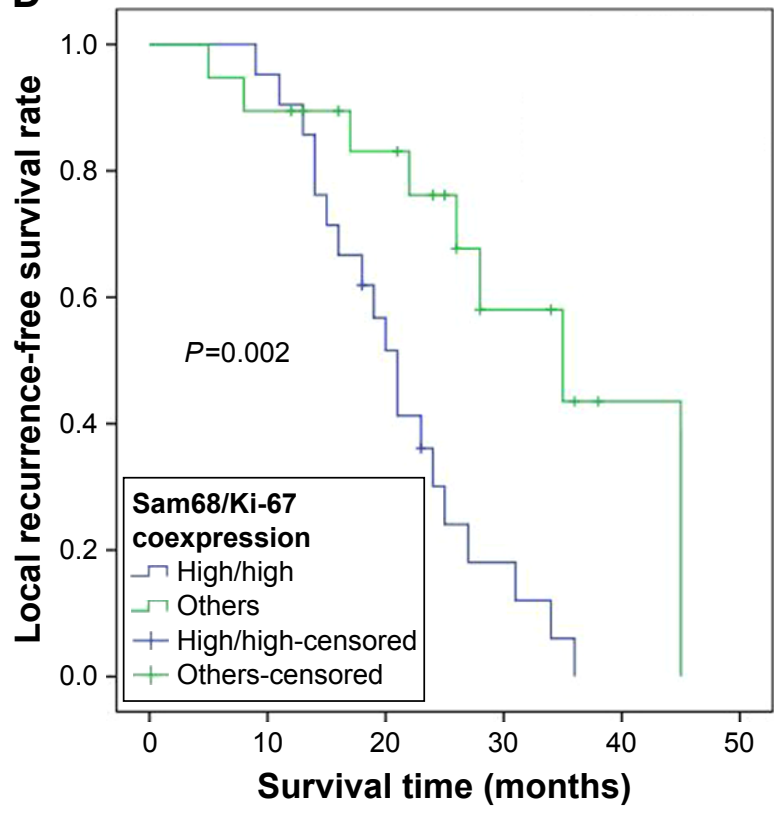

Figure 2 (Continued) 

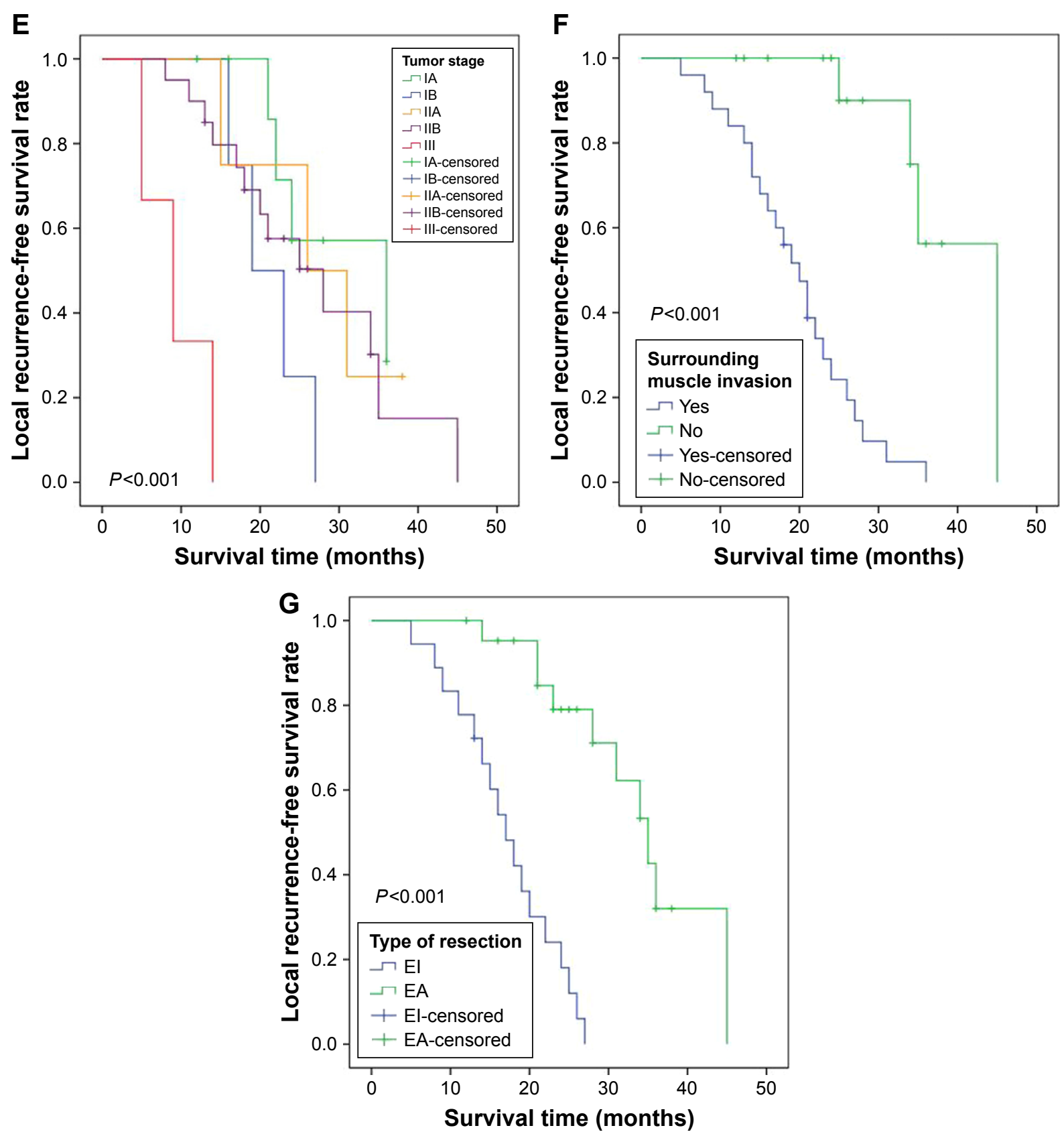

Figure 2 Kaplan-Meier curves of the local recurrence-free survival of patients with sacral chordoma.

Notes: (A) Stratified by Sam68 expression; (B) stratified by Ki-67 index; (C) stratified by Sam68/Ki-67 coexpression (low/low and others); (D) stratified by Sam68/Ki-67 coexpression (high/high and others); (E) stratified by tumor stage; (F) stratified by surrounding muscle invasion; (G) stratified by the type of tumor resection.

Abbreviations: EA, Enneking appropriate; El, Enneking inappropriate.

with tumor invasion into the surrounding muscles and poor LRFS of patients with sacral chordoma. Moreover, Sam68 was statistically identified as an independent prognostic factor for the LRFS. Our data suggest the use of Sam68 as a predictor for tumor recurrence.

Sam 68 has been identified as an RNA-binding protein and an adaptor recruiting other signaling molecules. ${ }^{29}$ Previous studies have demonstrated the significance of Sam68 in carcinogenesis; some of them support the promoting effect of Sam68 on tumor development, ${ }^{36,37}$ whereas others have shown the tumor suppressive function of Sam68. ${ }^{40}$ In this study, we observed an upregulation of Sam68 expression in sacral chordoma compared with normal tissues and found a positive correlation between the expression of Sam68 and cell proliferation index Ki-67, indicating that Sam68 probably promotes the growth of chordomas. The potential effect of Sam68 on the proliferation of chordoma cells is supported by the association between upregulation of Sam68 expression and cell proliferation in various cancers such as human prostate cancer and breast cancer. ${ }^{35,37}$ Additionally, Sam68 
Table 3 Kaplan-Meier analysis and multivariate Cox's proportional hazard analysis of the prognostic factors for the local recurrencefree survival of patients with sacral chordoma

\begin{tabular}{|c|c|c|c|c|}
\hline \multirow[t]{2}{*}{ Variables } & \multirow[t]{2}{*}{ Categories } & \multirow{2}{*}{$\frac{\text { Kaplan-Meier analysis }}{P \text {-value }}$} & \multicolumn{2}{|c|}{ Multivariate analysis } \\
\hline & & & $P$-value & HR (95\% CI) \\
\hline Age (years) & $<50 / \geq 50$ & 0.671 & & \\
\hline Gender & Male/female & 0.587 & & \\
\hline Tumor location & Above $S 3 / S 3$ and below & 0.091 & & \\
\hline Tumor size $(\mathrm{cm})$ & $<5 / \geq 5$ & 0.124 & & \\
\hline Tumor grade & High/low & 0.595 & & \\
\hline Tumor stage & $|\mathrm{A} /| \mathrm{B} / \mathrm{II} / \mathrm{IIB} / \mathrm{II}$ & $<0.001$ & 0.001 & $2.272(1.384-3.729)$ \\
\hline Surrounding muscle invasion & Yes/no & $<0.00$ I & 0.001 & $13.128(2.793-61.698)$ \\
\hline Type of resection & EI/EA & $<0.001$ & 0.002 & $6.678(2.052-21.736)$ \\
\hline Ki-67 index & High/low & 0.016 & 0.552 & $0.658(0.166-2.613)$ \\
\hline Sam68 expression & High/low & $<0.00$ I & 0.039 & $5.929(1.092-32.188)$ \\
\hline \multirow[t]{3}{*}{ Sam68/Ki-67 coexpression } & Low/low & $<0.00 I^{*}$ & & \\
\hline & High/high & $0.002 *$ & & \\
\hline & High/low and low/high & & & \\
\hline
\end{tabular}

Note: *Not included in the multivariate analysis because the variables depend on the expression of Sam68 and Ki-67.

Abbreviations: EA, Enneking appropriate; El, Enneking inappropriate; HR, hazard ratio.

A

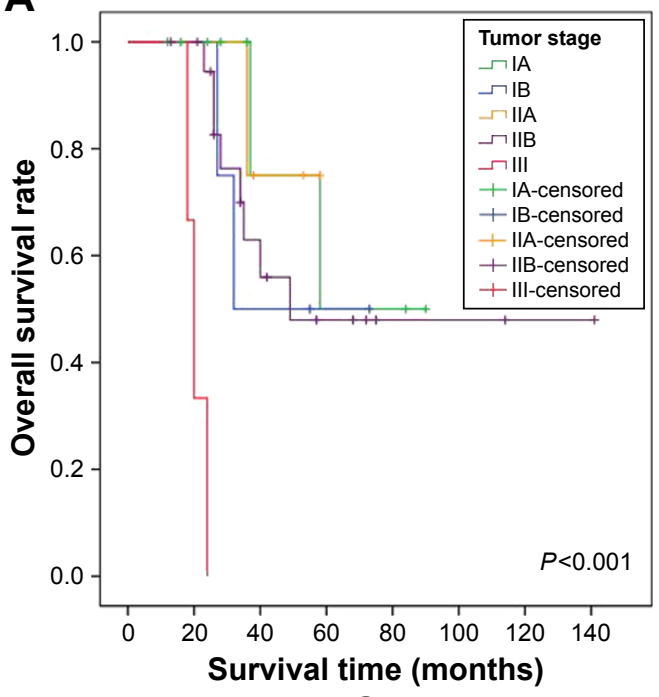

B

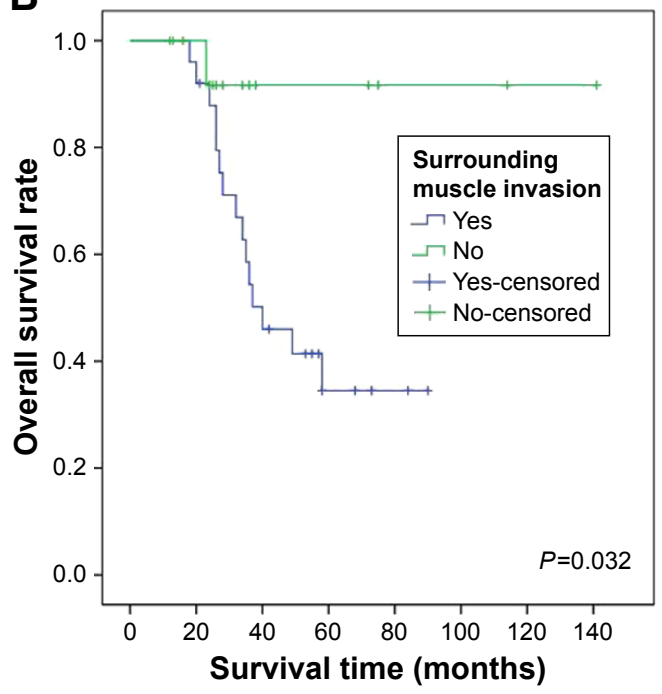

C

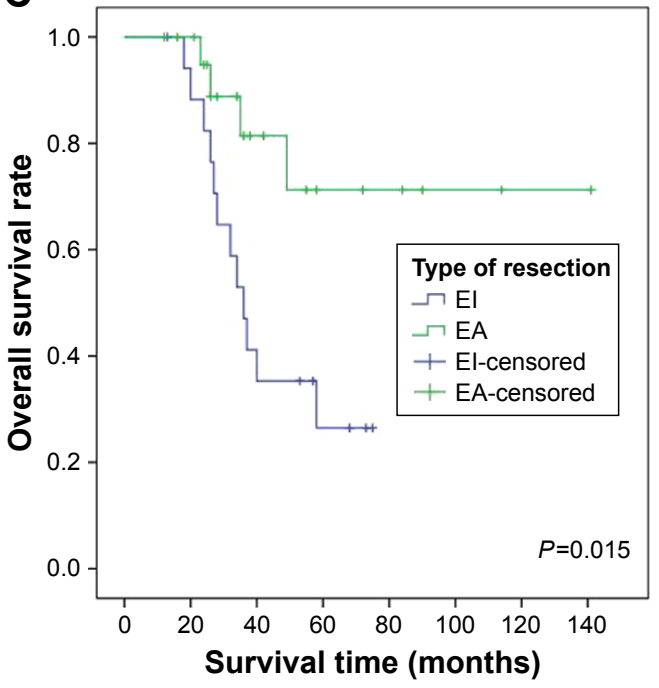

Figure 3 Kaplan-Meier curves of the overall survival of patients with sacral chordoma.

Notes: (A) Stratified by tumor stage; (B) stratified by surrounding muscle invasion; (C) stratified by the type of tumor resection.

Abbreviations: EA, Enneking appropriate; El, Enneking inappropriate. 
Table 4 Kaplan-Meier analysis and multivariate Cox's proportional hazard analysis of the prognostic factors for the overall survival of patients with sacral chordoma

\begin{tabular}{|c|c|c|c|c|}
\hline \multirow[t]{2}{*}{ Variables } & \multirow[t]{2}{*}{ Categories } & \multirow{2}{*}{$\begin{array}{l}\text { Kaplan-Meier analysis } \\
P \text {-value }\end{array}$} & \multicolumn{2}{|c|}{ Multivariate analysis } \\
\hline & & & $P$-value & HR (95\% CI) \\
\hline Age (years) & $<50 / \geq 50$ & 0.362 & & \\
\hline Gender & Male/female & 0.319 & & \\
\hline Tumor location & Above S3/S3 and below & 0.075 & & \\
\hline Tumor size $(\mathrm{cm})$ & $<5 / \geq 5$ & 0.065 & & \\
\hline Tumor grade & High/low & 0.468 & & \\
\hline Tumor stage & $|\mathrm{A} /| \mathrm{B} / \mid \mathrm{IA} / \mathrm{I} \mathrm{B} / \mathrm{II}$ & $<0.001$ & 0.049 & $1.677(1.002-2.806)$ \\
\hline Surrounding muscle invasion & Yes/no & 0.032 & 0.089 & $6.272(0.755-52.075)$ \\
\hline Type of resection & $\mathrm{El} / \mathrm{EA}$ & 0.015 & 0.175 & $2.254(0.697-7.291)$ \\
\hline Ki-67 index & High/low & 0.628 & & \\
\hline Sam68 expression & High/low & 0.228 & & \\
\hline \multirow[t]{3}{*}{ Sam68/Ki-67 coexpression } & Low/low & 0.250 & & \\
\hline & High/high & 0.547 & & \\
\hline & High/low and low/high & & & \\
\hline
\end{tabular}

Abbreviations: EA, Enneking appropriate; El, Enneking inappropriate; HR, hazard ratio.

was observed to be prominently located in the nucleus of sacral chordoma cells, which is consistent with the results of several reports demonstrating that Sam68 is a nuclear protein involved in gene transcription, alternative splicing and nuclear export. ${ }^{27,32,34,49}$ However, cytoplasmic Sam68 also plays a significant role in the progression of certain human cancers. ${ }^{37,50}$ The inconsistent localization of Sam68 is probably due to its different roles in multiple signaling pathways that affect the development of tumors. Thus, the significance of the nuclear localization of Sam 68 in chordoma cells should be further explored.

The association between Sam68 expression and the clinical data of tumor patients has been widely investigated previously. For example, high expression of Sam68 is associated with higher tumor stage and poorer recurrence-free survival of patients with bladder cancer; ${ }^{51}$ Sam68 is also involved in the progression of neuroblastoma and has a predictive significance for the prognosis of patients with neuroblastoma. ${ }^{46}$ In this study, we demonstrated a significant association between high Sam68 expression and surrounding muscle invasion of sacral chordomas and shorter LRFS of patients with sacral chordoma. Moreover, the results of multivariate analysis indicated that Sam68 can be used as an independent prognostic biomarker for the recurrence of sacral chordomas. Promoting the proliferation of residual chordoma cells after surgical resection may be one of the mechanisms of how Sam68 modulates the recurrence of sacral chordomas, whereas more detailed evidence needs to be further explored. Based on our results, we propose that surgeons should be more careful in choosing surgical strategies and try to achieve wide enough resection margins during tumor excision when high expression of Sam68 is determined using immunohistochemical analysis in patients with sacral chordoma who receive preoperative fine-needle aspiration biopsy; even if wide resection margin is achieved, patients with high levels of Sam68 should be warned of a relatively high risk of local tumor recurrence after the primary surgery and be followed up cautiously at short-term intervals for timely and effective treatment. It is worth mentioning that we did not observe an association between Sam68 expression and tumor size, grade or stage, which could be due to a small sample size, relatively low statistical power or the influence of other risk factors. Although patients with sacral chordoma who had high Sam68 levels did not show reduced OS in our study, more evidence is needed to rule out a relationship between Sam68 expression and the OS.

In summary, we demonstrated that high expression of Sam68 in sacral chordomas is significantly associated with worse clinical outcomes. Our findings suggest that Sam68 can be used as a predictor for the recurrence of sacral chordomas.

\section{Acknowledgment}

This work was supported by the Fundamental Research Funds for the Central Universities of Central South University (No 2016zzts149).

\section{Disclosure}

The authors report no conflicts of interest in this work.

\section{References}

1. Stiller CA, Trama A, Serraino D, et al; RARECARE Working Group. Descriptive epidemiology of sarcomas in Europe: report from the RARECARE project. Eur J Cancer. 2013;49(3):684-695. 
2. Casali PG, Stacchiotti S, Sangalli C, Olmi P, Gronchi A. Chordoma. Curr Opin Oncol. 2007;19(4):367-370.

3. McMaster ML, Goldstein AM, Bromley CM, Ishibe N, Parry DM. Chordoma: incidence and survival patterns in the United States, 1973-1995. Cancer Causes Control. 2001;12(1):1-11.

4. Walcott BP, Nahed BV, Mohyeldin A, Coumans JV, Kahle KT, Ferreira MJ. Chordoma: current concepts, management, and future directions. Lancet Oncol. 2012;13(2):e69-e76.

5. Chugh R, Tawbi H, Lucas DR, Biermann JS, Schuetze SM, Baker LH. Chordoma: the nonsarcoma primary bone tumor. Oncologist. 2007; 12(11):1344-1350

6. Tzortzidis F, Elahi F, Wright D, Natarajan SK, Sekhar LN. Patient outcome at long-term follow-up after aggressive microsurgical resection of cranial base chordomas. Neurosurgery. 2006;59(2):230-237; discussion 230-237.

7. Samson IR, Springfield DS, Suit HD, Mankin HJ. Operative treatment of sacrococcygeal chordoma. A review of twenty-one cases. $J$ Bone Joint Surg Am. 1993;75(10):1476-1484.

8. Smith J, Ludwig RL, Marcove RC. Sacrococcygeal chordoma. A clinicoradiological study of 60 patients. Skeletal Radiol. 1987;16(1):37-44.

9. Sundaresan N, Huvos AG, Krol G, Lane JM, Brennan M. Surgical treatment of spinal chordomas. Arch Surg. 1987;122(12):1479-1482.

10. Hulen CA, Temple HT, Fox WP, Sama AA, Green BA, Eismont FJ Oncologic and functional outcome following sacrectomy for sacral chordoma. J Bone Joint Surg Am. 2006;88(7):1532-1539.

11. Catton C, O'Sullivan B, Bell R, et al. Chordoma: long-term follow-up after radical photon irradiation. Radiother Oncol. 1996;41(1):67-72.

12. Cheng EY, Ozerdemoglu RA, Transfeldt EE, Thompson RC Jr. Lumbosacral chordoma. Prognostic factors and treatment. Spine (Phila Pa 1976). 1999;24(16):1639-1645.

13. Azzarelli A, Quagliuolo V, Cerasoli S, et al. Chordoma: natural history and treatment results in 33 cases. J Surg Oncol. 1988;37(3):185-191.

14. York JE, Kaczaraj A, Abi-Said D, et al. Sacral chordoma: 40-year experience at a major cancer center. Neurosurgery. 1999;44(1):74-79; discussion 79-80.

15. Stacchiotti S, Sommer J; Chordoma Global Consensus Group. Building a global consensus approach to chordoma: a position paper from the medical and patient community. Lancet Oncol. 2015;16(2):e71-e83.

16. Burd CG, Dreyfuss G. Conserved structures and diversity of functions of RNA-binding proteins. Science. 1994;265(5172):615-621.

17. Johnson DL, Johnson SA. Cell biology. RNA metabolism and oncogenesis. Science. 2008;320(5875):461-462.

18. Rajan P, Gaughan L, Dalgliesh C, et al. Regulation of gene expression by the RNA-binding protein Sam68 in cancer. Biochem Soc Trans. 2008;36(Pt 3):505-507.

19. Lukong KE, Richard S. Sam68, the KH domain-containing superSTAR. Biochim Biophys Acta. 2003;1653(2):73-86.

20. Huot ME, Vogel G, Zabarauskas A, et al. The Sam68 STAR RNAbinding protein regulates mTOR alternative splicing during adipogenesis. Mol Cell. 2012;46(2):187-199.

21. Iijima $\mathrm{T}, \mathrm{Wu} \mathrm{K}$, Witte $\mathrm{H}$, et al. SAM68 regulates neuronal activitydependent alternative splicing of neurexin-1. Cell. 2011;147(7): 1601-1614.

22. Bielli P, Busa R, Paronetto MP, Sette C. The RNA-binding protein Sam68 is a multifunctional player in human cancer. Endocr Relat Cancer. 2011;18(4):R91-R102.

23. Henao-Mejia J, Liu Y, Park IW, Zhang J, Sanford J, He JJ. Suppression of HIV-1 Nef translation by Sam68 mutant-induced stress granules and nef mRNA sequestration. Mol Cell. 2009;33(1):87-96.

24. Rajan P, Gaughan L, Dalgliesh C, et al. The RNA-binding and adaptor protein Sam68 modulates signal-dependent splicing and transcriptional activity of the androgen receptor. $J$ Pathol. 2008;215(1):67-77.

25. Richard S. Reaching for the stars: Linking RNA binding proteins to diseases. Adv Exp Med Biol. 2010;693:142-157.

26. Sette C. Post-translational regulation of star proteins and effects on their biological functions. Adv Exp Med Biol. 2010;693:54-66.

27. Matter N, Herrlich P, Konig H. Signal-dependent regulation of splicing via phosphorylation of Sam68. Nature. 2002;420(6916):691-695.
28. Paronetto MP, Messina V, Bianchi E, et al. Sam68 regulates translation of target mRNAs in male germ cells, necessary for mouse spermatogenesis. J Cell Biol. 2009;185(2):235-249.

29. Najib S, Martin-Romero C, Gonzalez-Yanes C, Sánchez-Margalet V. Role of Sam68 as an adaptor protein in signal transduction. Cell Mol Life Sci. 2005;62(1):36-43.

30. Ramakrishnan P, Baltimore D. Sam68 is required for both NF-kappaB activation and apoptosis signaling by the TNF receptor. Mol Cell.2011; 43(2):167-179.

31. Chawla G, Lin CH, Han A, Shiue L, Ares M Jr, Black DL. Sam68 regulates a set of alternatively spliced exons during neurogenesis. $\mathrm{Mol}$ Cell Biol. 2009;29(1):201-213.

32. Paronetto MP, Cappellari M, Busa R, et al. Alternative splicing of the cyclin D1 proto-oncogene is regulated by the RNA-binding protein Sam68. Cancer Res. 2010;70(1):229-239.

33. Cheng C, Sharp PA. Regulation of CD44 alternative splicing by SRm160 and its potential role in tumor cell invasion. Mol Cell Biol. 2006;26(1):362-370.

34. Paronetto MP, Achsel T, Massiello A, Chalfant CE, Sette C. The RNAbinding protein Sam68 modulates the alternative splicing of Bcl-x. J Cell Biol. 2007;176(7):929-939.

35. Busa R, Paronetto MP, Farini D, et al. The RNA-binding protein Sam68 contributes to proliferation and survival of human prostate cancer cells. Oncogene. 2007;26(30):4372-4382.

36. Wang Y, Liang L, Zhang J, et al. Sam68 promotes cellular proliferation and predicts poor prognosis in esophageal squamous cell carcinoma. Tumour Biol. 2015;36(11):8735-8745.

37. Song L, Wang L, Li Y, et al. Sam68 up-regulation correlates with, and its down-regulation inhibits, proliferation and tumourigenicity of breast cancer cells. J Pathol. 2010;222(3):227-237.

38. Wang Q, Li Y, Zhou J, et al. Clinical significance of Sam68 expression in endometrial carcinoma. Tumour Biol. 2015;36(6):4509-4518.

39. Li Z, Yu CP, Zhong Y, et al. Sam68 expression and cytoplasmic localization is correlated with lymph node metastasis as well as prognosis in patients with early-stage cervical cancer. Ann Oncol. 2012;23(3):638-646.

40. Taylor SJ, Resnick RJ, Shalloway D. Sam68 exerts separable effects on cell cycle progression and apoptosis. BMC Cell Biol. 2004;5:5.

41. Kayani B, Hanna SA, Sewell MD, Saifuddin A, Molloy S, Briggs TW. A review of the surgical management of sacral chordoma. Eur J Surg Oncol. 2014;40(11):1412-1420.

42. Jemal A, Siegel R, Ward E, Murray T, Xu J, Thun MJ. Cancer statistics, 2007. CA Cancer J Clin. 2007;57(1):43-66.

43. Fisher CG, Saravanja DD, Dvorak MF, et al. Surgical management of primary bone tumors of the spine: validation of an approach to enhance cure and reduce local recurrence. Spine (Phila Pa 1976). 2011;36(10): 830-836.

44. Zhou M, Chen K, Yang H, et al. Expression of insulin-like growth factor II mRNA-binding protein 3 (IMP3) in sacral chordoma. $J$ Neurooncol. 2014;116(1):77-82.

45. Han W, Ming M, He TC, He YY. Immunosuppressive cyclosporin A activates AKT in keratinocytes through PTEN suppression: implications in skin carcinogenesis. J Biol Chem. 2010;285(15):11369-11377.

46. Zhao X, Li Z, He B, et al. Sam68 is a novel marker for aggressive neuroblastoma. Onco Targets Ther. 2013;6:1751-1760.

47. Bergh P, Kindblom LG, Gunterberg B, Remotti F, Ryd W, MeisKindblom JM. Prognostic factors in chordoma of the sacrum and mobile spine: a study of 39 patients. Cancer. 2000;88(9):2122-2134.

48. Kayani B, Sewell MD, Tan KA, et al. Prognostic factors in the operative management of sacral chordomas. World Neurosurg. 2015;84(5): 1354-1361.

49. Chen T, Boisvert FM, Bazett-Jones DP, Richard S. A role for the GSG domain in localizing Sam68 to novel nuclear structures in cancer cell lines. Mol Biol Cell. 1999;10(9):3015-3033.

50. Richard S, Vogel G, Huot ME, Guo T, Muller WJ, Lukong KE. Sam68 haploinsufficiency delays onset of mammary tumorigenesis and metastasis. Oncogene. 2008;27(4):548-556.

51. Zhang Z, Yu C, Li Y, Jiang L, Zhou F. Utility of SAM68 in the progression and prognosis for bladder cancer. BMC Cancer. 2015;15:364 


\section{Publish your work in this journal}

OncoTargets and Therapy is an international, peer-reviewed, open access journal focusing on the pathological basis of all cancers, potential targets for therapy and treatment protocols employed to improve the management of cancer patients. The journal also focuses on the impact of management programs and new therapeutic agents and protocols on

patient perspectives such as quality of life, adherence and satisfaction. The manuscript management system is completely online and includes a very quick and fair peer-review system, which is all easy to use. Visit http://www.dovepress.com/testimonials.php to read real quotes from published authors.

Submit your manuscript here: http://www.dovepress.com/oncotargets-and-therapy-journal 